\title{
We do not have a spare Earth
}

\author{
J. T. Trevors • M. H. Saier Jr.
}

Published online: 6 April 2010

(C) Springer Science+Business Media, LLC 2010

The manner in which our common biosphere on the Earth is assaulted would lead humans to believe we have a spare Earth to use when this one has been damaged beyond repair. We do not have a spare Earth. Damage that is inflicted daily in our common biosphere includes global pollution of our water, air and soil environments, increased human population numbers, depletion of non-renewable resources, immense human suffering and death via conflicts and wars, species extinctions, loss of biodiversity, failure to conserve resources, failure to adequately educate humans and the list goes on. In fact, humans do not have any estimates of how long a technological civilization can survive with our increasing use of resources and increasing human population growth. An increasing human population and consumption of resources driven by economic growth and greed really means we need a spare planet Earth now, not in a few decades.

Trading carbon credits will not decrease the number of humans on this planet nor will it sustain our common biosphere. Capitalism is not free access to polluting our common biosphere for economic gains while human population growth increases and resources decrease. Since a spare Earth does not exist, human population growth must decrease which will allow depletion of resources to be slowed until global programs can be implemented to reduce pollution and consumption.

J. T. Trevors $(\bowtie)$

Department of Environmental Biology, University of Guelph,

Guelph, ON N1G 2W1, Canada

e-mail: jtrevors@uoguelph.ca

M. H. Saier Jr. ( $ه)$

Division of Biological Sciences, University of California,

San Diego, La Jolla, CA 92093-0116, USA

e-mail: msaier@ucsd.edu
Have educational institutions failed to teach past generations and the current generation that damaging environmental, political, social, technological and military activities are not acceptable in a common biosphere? Or do people ignore the knowledge and information that is available and proceed to live an unsustainable life style at the expense of future generations their children and grandchildren? Why would they think that future generations will live better lives than the current generation? There are no spare parts to fix or patch up the Earth with. Humans have to limit their population growth, especially in large cities which are not sustainable from energy, food, water and transportation perspectives. Yet, cities are the very locations where human population densities are increasing and where infectious diseases/pandemics would cause the most deaths and human suffering.

The living organisms including humans in our common biosphere follow a simple set of rules. Some organisms live and reproduce, some live and do not reproduce and some die before they reproduce. This applies to all species. The resources available on the Earth must be sufficient to meet the needs of humans and all other species now and in the future. This can not be achieved without correctly reducing human population growth and how energy and other natural resources are utilized. There are already too many humans subjected to immense suffering and death. An increasing human population will only worsen the situation in the future. 